\title{
Something old, something blue: bereavement and institutional ageism in The Gigantic Beard That Was Evil
}

\author{
Marissa Lammon ${ }^{1}$ \\ ${ }^{1}$ Media Studies, University of Colorado at Boulder, Boulder, Colorado, USA Email: m.lammon@outlook.com
}

(Accepted 13 August 2021)

\begin{abstract}
The dystopian fiction genre within Western media has historically highlighted the flaws associated with societal attempts to achieve an unattainable ideal - or utopia. Through storytelling, these texts highlight the present issues in society, and among them, readers find deeply concerning messages about dehumanisation and oppression. The Gigantic Beard That Was Evil by Stephen Collins is uniquely placed within this larger genre due to the exceptional use of negative space; that is, the text communicates multiple meanings through what Collins includes and does not include. The following article engages in a deep reading of The Gigantic Beard That Was Evil through textual analysis to interpret and describe the message Collins communicates highlighting institutional ageism and bereavement. Consideration for the use of both negative and positive space within narrative construction reveals a story that encourages societal and social change to better care for the mentally ill, geriatric population.
\end{abstract}

Keywords: ageism; mental health; stigmatisation; bereavement; negative space

\section{Introduction}

Western media has historically checked quite a few repetitive boxes in the entertainment industry - intense, climactic and, oftentimes, utopian (McKee et al., 2012: 23). The trope in Western narrative of a misguided attempt to create utopia by limiting the boundaries of society appears time and again across platforms and occupies its own genre: dystopian fiction. In these worlds, authors create visions of the future rife with oppression and dehumanisation that exist as a result of attempted utopian gain; and in this way, readers are often encouraged to challenge their preconceived notions about social and political moments. In some versions, such as The Hunger Games or Nineteen Eighty-Four, the dystopia is immediately identified as an abuse of power. In others, such as The Giver or Divergent, audiences are made to believe that the collective society has chosen the conformity as a means to create an ideal world (that ultimately fails); and in others, like The Gigantic Beard 
That Was Evil, audiences are encouraged to look beyond the simple words or images that are provided to them and discover the hidden messages of dystopia and corrupt societal structures within the narrative.

The Gigantic Beard That Was Evil by Stephen Collins is a New York Times bestselling graphic novel and winner of the Inaugural 9th Art Award (Collins, 2014). The story follows not only the tidy townspeople of 'Here', but a man noticeably distinguished from the rest. The novel begins by creating a foundation for an understanding of Here - a place described explicitly as 'perfect' (Collins, 2014). This is juxtaposed to the frightening 'There' and the sea that leads to it; contrary to Here, There is 'disorder ... chaos ... evil' (Collins, 2014). As the protagonist, Dave, navigates through the tidiness in Here, he attempts to drown out his growing fears but is forced to confront a wave of anxiety and oppression after the single hair below his nose turns into an uncontrollable beard engulfing most of the town. While the novel has been described as an allegorical fable wherein Collins stresses the dangers of conformity and fear, the purposeful choices made by Collins surrounding Dave's appearance, behaviour and treatment bring alternative interpretations to the surface (Turner, 2014). Through detailed artwork and images that extend across multiple panels, Collins manages to produce a text that, where whimsical in a rudimentary sense, illustrates the use of media as a catalyst for social change.

Although Western media is predominately categorised as entertainment, several media texts have demonstrated the ability to entertain, while at the same time, teach. Comedic films such as Click or Yes Man are designed to not only make audiences laugh but also communicate deeper life lessons about enjoying the time one has left. Similar profound messaging can be found in animated films targeted at children - Frozen, Moana, Soul; animated films are utilising the creative space that animation offers to challenge faulty societal thinking such as conformity and fear. In order to do so, these films often showcase the bad - a society that excludes members that are different or forcefully restricts self-expression. Collins adopts a similar strategy, by strategically depicting a society wherein specific groups of people are isolated, through texts and images both in manifest and latent content; by doing so, Collins communicates powerful messages that problematise current societal treatment of the geriatric population.

The purpose of this article is to interpret and describe the message Collins communicates beyond the surface-level use of images and dialogue - a message that highlights institutional ageism and exists within a problematic cultural climate that stigmatises not only ageing, but mental health as well. The need to address these concerns is intensified with new changes to medical practices that further isolate the geriatric population battling comorbidity. As criteria for diagnosing mental health disorders become more advanced, new diagnoses arise due to changing diagnostic criteria. Among the deviations is the separation of depression as a result of bereavement from the diagnosable Major Depressive Disorder. The most recent version of the Diagnostic and Statistical Manual of Mental Disorders (American Psychiatric Association, 2013) outlines several criteria for Major Depressive Disorder related to mood, weight fluctuation, sleep disturbances, concentration and thoughts of death; notably, the criteria require the symptoms be separate from substance use or other medical conditions but does not otherwise attempt to indicate a cause or source of the depression. Yet, a separate disorder - identified 
as Persistent Complex Bereavement Disorder - attempts to separate depression as a result of bereavement. The symptoms and criteria for diagnosis are built around what is considered a socially and culturally acceptable amount of time to grieve the loss of a loved one, alongside cognitive or behavioural changes (Nielson et al., 2017; Fleming, 2021). While the separation can be seen as an attempt to better specify the source of depressive thoughts and behaviours, it can also be seen as a disregard or negligence of specific demographics, primarily older adults.

Geriatric patients are frequently identified as a high-risk population for depression based on prevalence rates and statistics (Rapp et al., 1988). Studies have indicated that despite efforts to increase screening, proper medical diagnosis of depression in geriatric patients is extremely low, and older adults remain largely misdiagnosed; even more problematic, the geriatric patients that do receive a diagnosis are largely untreated (Rapp et al., 1988; Bruce et al., 2002). Still, depression and mental health differences among geriatric populations is but one small piece to a much larger puzzle of ageism in health care and, in turn, ageism in society. The discussions surrounding ageism in health care have been intrinsically tied to discussions surrounding ageism in the larger civilisation - that is, arguments in favour of common ageist practices pull from the belief that older adults 'are disproportionately heavy users of medical care' with an increased burden of illness and supposed favouritism through programmes such as Medicare (Kane and Kane, 2005: 49). A reoccurring theme in the discussions of resources for the geriatric population remains a concern over value of human life as a function to the larger society.

\section{Method}

With heavy topics such as mental health, bereavement and ageism at the forefront of discussion, the natural tendency to focus on what is present becomes a forefront of analysis. Researchers, scholars, physicians and parents all want to know what is being talked about, what is being presented, and how these discourses are helpful or problematic to different areas of society and social presence; but what is missing from these discussions is, ironically, what is missing. A valuable component to textual analysis involves consideration of the unrepresented within a text - specifically examining the systematic exclusion of representations that are often overlooked (McKee, 2003: 110). In an artistic sense, artists use this 'negative space', 'the unmarked areas of the page', to create an entirely separate image than the one occupied in the subject, or positive space (Wong, 2011: 1). Media research has pulled from this notion that multiple messages can be communicated simultaneously, in real time, by examining not only what texts are communicating through presence, but absence as well. Even beyond the visual, research has explored how silence communicates an entirely independent picture of the one created with spoken word (Ward and Winstanley, 2003). In this way, media analyses take into equal consideration how what is not present influences the message and interpretation of a text as that of what is present.

Given the primary goal of determining and interpreting the message within the negative space of Collins' piece, a textual analysis that utilises deep reading appropriately takes into consideration the elemental components to the text while including analyses to examine what the observed elements offer in terms of message 
construction. The following analysis is derived from multiple readings of the text that resembles a three-tier analysis to approaching textual analysis of media. These multiple readings include an initial reading that addresses the text, the story, the events and the characters; a second reading that addresses the images and dialogue; and a third reading that addresses the meaning and significance of the text as a whole. ${ }^{1}$ The first reading sets a foundation for understanding the positive and negative spaces within a specific text - that is, in the first reading, the researcher considers the different fundamental elements put forth by an author. In the second reading, there is an increased focus on the images and dialogue, including how they are presented, how they intertwine or complement one another, and how they also create a foundation for the narrative. The third reading involves the highest level of subjectivity wherein the researcher comes to an interpretation of what the text means and how it is significant in larger contexts. This deep-reading strategy is built upon the three necessary criteria for a critical visual methodology: 'takes images seriously, thinks about the social conditions and effects of images and their mode of distribution, (and) considers [one's] own way of looking at images' (Rose, 2016: 22).

Although the third reading results in a noticeably subjective interpretation, the entire process of deep reading and textual analysis is subjective and creates limitations when considering bias. The way one learns and exists in the world creates a bias and subjective lens through which media are interpreted and can therefore influence concluding thoughts or interpretations of media texts. As noted in the third listed criteria for critical visual methodology outlined above, researchers must consider their own way of looking at and interpreting images to draw conclusions and pursue valid interpretations effectively. While the final interpretation is still considered subjective, it is this subjectivity that - when paired with acknowledgement and introspection - leads to a variety of different ways to read and examine media texts.

This three-tier deep reading textual analysis strategy places the single media text within a larger societal context and therefore addresses more than just a piece of media. By examining the text in detail alongside the current historical and social moment, a textual analysis of this piece offers a qualitative examination of meaning and context. Specifically, the following article addresses the problematic narrative centred on ageism and bereavement that is illuminated after thorough investigation of the negative space in The Gigantic Beard That Was Evil.

\section{Discussion}

In a society where 'tidiness' is prioritised, self-image and presentation are extremely valued and therefore important features to consider in analysis. Collins creates a society so 'neat' and uniform that any deviation from the 'norm' is immediately recognisable and problematic. The deviations that Dave exhibits - both in the positive and negative space - set him apart from the rest of the population on the basis of age and mental health.

\section{Age}

The major difference between Dave and the people of Here is a generational gap indicated through Dave's advanced age. The specific age of characters is not 
explicitly discussed throughout the narrative; however, specific choices in character development and images alongside analysis of the negative space indicate Dave's status as an older adult. Particularly, Collins pulls from both biological and social indicators of age when constructing the image of his aged protagonist.

\section{Biological indicators}

As the audience discovers through Dave's drawings, the physical similarities between each passerby lies within the absence of facial hair (Collins, 2014). In fact, nearly all of the men pictured in Dave's drawings (and Collins' entire novel) exhibit no defining features that distinguish them from one another, particularly as it applies to age. Dave, on the other hand, exemplifies two different physical features that identify him as an older adult, each associated with the location of hair. Where his newfound beard is a powerful symbol for his evolving depression, his facial hair is - at its most fundamental level - a physical marker of biological maturity in men (Miller, 2017). Though Dave is presented as the only individual with hair upon his face, he is also presented as the only individual with no hair atop his head. Similar to the growth of facial hair, hair loss is a biological indicator of ageing (Levine, 2016). The audience is told from the start of the novel that Dave currently wears a wig and that even his 'pre-wig days' featured baldness - suggesting that having been bald for a substantial amount of time, Dave is significantly older than most of the characters with whom he interacts (Collins, 2014).

\section{Social indicators}

Beyond the physical components revealing Dave's age, an examination of the negative space further indicates his status as an older citizen. Praised for his intricate sketch-work and panel placement, Collins meticulously and purposefully includes images that are essential to the novel's development. Within the text, nearly 50 panels - several occupying close to half a page - are devoted to depicting citizens engaged with their cell phones (Collins, 2014). In direct contrast to the rest of society, Dave's few interactions with technology are limited to computers and projectors at work as well as his wired phone at home (Collins, 2014). Dave is never seen interacting with a cell phone, and resorts to a basic portable cassette player similar to those developed by Sony in 1979. In the negative space, the reader discovers that Dave does not possess the same level of technological awareness and accessibility as the average person, further contributing to his identification as an older adult.

\section{Bereavement}

As the only geriatric individual depicted in the novel, Dave struggles with very common geriatric-specific obstacles - among them is his visible battle with bereavement. The death of a loved one is not only tragic in the moment but has lasting impact on an individual's life as well as his or her daily behaviours and thoughts (Rees and Lutkins, 1967). Collins provides his readers with a glimpse of mortality and the processes of grief primarily through Dave's solemn solitude and overwhelming fear of death. 


\section{Solitude}

Where Collins does well to include detailed, transcribed intricacies that provide a basis for the ample amount of valid textual interpretations, a key underrepresentation in the manifest content that is disregarded lies within the main character's solitude. When not engaging with his primary emotional outlet of drawing, Dave's expression while alone within the home is glum - his head hangs down and he looks to the floor when showering, brushing his teeth, and entering or leaving through the front door (Collins, 2014). The emphasis on Dave's solitude while in the home is disconcerting and becomes a key component to the development of his character. Dave does not interact with townspeople outside typical work exchanges and arrives at the end of long, dull days to an empty home. Through the panels that focus on Dave's solitude inside his home, it can be suggested that Dave did - at one point - live with a companion. The entrance of Dave's home is notably patterned with a floral wallpaper, and a large coat rack stands by the doorway - currently only used to a very small degree by Dave's wig on a single hook (Collins, 2014).

This creates a source of inquisitiveness within readers regarding Dave's living situation prior to the current setting. This ambiguity is addressed in several stages by Collins - the first being the foundation he lays with Dave as an artist who draws what he sees. Dave's drawings are always distinguished from Collins' own drawings in the novel through much lighter sketching. As readers follow Dave's daily routine, the darkened panels by Collins to portray Dave's bus ride are interrupted by a series of lightly sketched panels that depict a man exiting the back of an ambulance with a stretcher (Collins, 2014). In this moment, Dave's initial facial expression of concern fades to one of sorrow - it could be that Dave has experienced a 'flash-back' to a previously witnessed traumatic event, one related to the death of his absent companion. Collins further pushes this interpretation surrounding death and trauma through Dave's behaviours and thoughts surrounding death and uncertainty.

\section{Death anxiety}

Alone with no spousal figure or children and captivated by the love ballad Eternal Flame, Dave represents a bereaved care-giver coping with the death of a loved one. McKee (2003: 21) recognises the inevitability and exactness of death by claiming 'it's an experience that you can't escape just by interpreting it differently', but also suggests that differences in sense-making practices shape individual interpretations and value judgements regarding death as desirable, undesirable or even feared. As one of very few mammalian species aware of mortality, this self-knowledge frequently elicits a fear of death that is heightened by the confrontation of pain, suffering and death of others (Kauffman, 1995; Bachner et al., 2011). With the symbolic nature of There representing the inevitable death that accompanies mortality, Dave is particularly fearful of the unknown entity and any transporting feature associated with it. The reader first learns of this anxiety when the windowless walls of coastal houses are revealed to be a visual and mental avoidance of the Sea and the darkness with which it connects (Collins, 2014).

Dave's aversion to the symbolic representation of death becomes clearer when examining his isolation and the structured absence of a spousal figure. Death anxiety is closely related to actual confrontations with death, notably witnessing and 
understanding the death of another person (Sherman et al., 2010). Dave's death anxiety arises as a result of his experience with spousal death, evident not only through the absence of a spouse, but also his perpetual enthralment with Eternal Flame by The Bangles. Serving as a major inter-text, the lyrics contribute to the overall function of the song within the novel:

Close your eyes. Give me your hand, darling. Do you feel my heart beating? ... I watch you when you are sleeping. You belong with me ... Am I only dreaming, or is this burning an eternal flame? A whole life so lonely, and then you come and ease the pain. I don't want to lose this feeling. (Hoffs and Steinberg, 1989)

A musical representation of a complicated love scene, Eternal Flame suggests the continual burning of a flame in honour of a loved one - one that can never be extinguished, even in his or her absence. On constant repeat, the song drowns Dave's anxious thoughts and becomes a means to avoid death-related contemplations (Collins, 2014). This is largely due to the tendency of care-givers that experience the death of their 'patient' to engage in protective behaviours that avoid fears and concerns associated with the inevitable demise (Vess et al., 1988; Edwards and Foster, 1999). As a result, bereaved care-givers suffering from death anxiety are less likely to communicate their fears or negative feelings, hence Dave's attempts to present a neat and 'tidy' image to the public while passively drowning out any disturbing and anxious cognitions (Bachner et al., 2011; Collins, 2014).

\section{Mental health}

Despite Dave's efforts to subdue his anxious thoughts, the plethora of negative cognitions that arise as a result of witnessing spousal death becomes overwhelming. Accompanied with death anxiety, studies have shown that 'a considerable proportion of bereaved caregivers develop complicated grief or post-loss depressive symptoms' (Nielson et al., 2017: 540) after the patient's death, and the depressive symptoms are magnified if the care-giver is the patient's spouse (Tang et al., 2013: 1316). Collins utilises symbolism to depict Dave's bereavement by allowing the growing, black beard to function as depression. Continuously present through the single hair under his nose, Dave's depression is always breaching the surface, but appears to be, for the most part, maintained through regular doctor visits and close attention to any growth or change:

$\begin{array}{ll}\text { Doctor Peterson: } & \text { Neither thinner nor stronger? } \\ \text { Dave: } & \text { No. } \\ \text { Doctor Peterson: } & \text { Shorter no longer? } \\ \text { Dave: } & \text { No. Just the same as it was before. } \\ \text { Doctor Peterson: } & \text { Remarkable. (Collins, 2014) }\end{array}$

Dave explains to Doctor Peterson that the hair had 'always just been ... there' and compares his abnormality to the dark unknown that haunts him - the purposefully named mysterious entity, 'There' (Collins, 2014). In this instance, we are given a direct comparison to the depressive emotions that Dave attempts to suppress and the death of which he has not only witnessed, but fears. As the plot develops, 
the connection is strengthened, and the failures associated with attempts to suppress grief become evident.

As a result of Dave's aged status, inadequate attention and care are devoted to his wellbeing and overall psychological state. Despite mental illness such as Major Depressive Disorder affecting over seven million seniors and 40-50 per cent of care-givers, depression in older patients is often incorrectly viewed by health-care professionals as 'an inevitable consequence of aging rather than an objective clinical diagnosis' (Briggs et al., 2018: 6). The misconception that depression is a consequence of ageing opposed to bereavement over lost loved ones 'leads to underdiagnosis and under-treatment by health care professionals' (Newman, 2017). These detrimental misconceptions result in the dismissal of Dave's concerns, and he receives little valuable assistance. Ambulance services abruptly end their phone call, Doctor Peterson sends Dave away to a 'specialist', and Professor Darren Black manipulates and exploits Dave's condition to the public (Collins, 2014).

\section{Institutional ageism}

With the examination of negative space contributing to a clearer image of Dave's character as an aged, bereaved care-giver struggling with mental health, the problematic assertions about ageism within this text continue to extend beyond the misdiagnosis of his depression. As an older adult struggling with mental health, Dave is viewed by the macro levels of society as an inconvenience, and by the micro levels as a flaw - two separate entities that Collins identifies as major contributors to institutional ageism both systemically and socially.

\section{Systemic}

An important feature to Dave's maltreatment is found in the society Collins presents - one that is critical of not only Dave's inability to subdue his implicit attitudes, but one that wishes to eliminate his very existence on the basis of fear and resentment. An entire panel is dedicated to a projection of 'USER Value' across Dave's chest as he gives a presentation to the younger generation about profit, value and productivity (Collins, 2014). The function of older adults in the larger society is also clear through explicit advertisements pasted around the town one sign reading, ' $F$ and G LIFE INSURANCE ... Making your death a lot better for everyone' (Collins, 2014). Visually, Collins offers readers a clear idea of how aged individuals are seen and valued within the culture.

This depiction of older adults as an inconvenience to larger societal goals is further emphasised by Collins through political decision making; the government calls for Dave's public execution claiming, 'if we can't cut it ... we have to kill it at source' (Collins, 2014). This proposed solution, by a government official, highlights the political assumptions that seniors 'waste' government resources - a political stance that has been observed in several different cultures. In 2013, Japan's financial minister expressed his concern for social security reforms, suggesting that 'the problem won't be solved unless you let them hurry up and die' (McCurry, 2013). Institutionally approaching health care with the mindset that a geriatric patient is invaluable to society and utilising valuable monetary resources undoubtedly results 
in the mistreatment of ageing mentally ill patients. The government of Here exemplifies a similar mindset in their suggestion of public execution as well as the solution to exile Dave and ultimately send him to his death in There (Collins, 2014).

\section{Social}

Although institutions hold a significant amount of power, the people within a culture collectively influence the decision-making processes. Dave not only becomes a threat to government resources, but a source of blame and protest by several townspeople:

They should just get rid of him

He's best off dead!

Terrorists must GO!

KILL THIS DEVIL. (Collins, 2014)

While Collins attributes this reaction to fear of change that ultimately creates the act of 'naming', the citizens' behaviour reveals the sense-making practices of most social beings (Collins, 2014). The fundamental attribution error explains the human tendency to attribute the behaviour of others to some internal disposition and attribute one's own behaviour to external situational factors (Tetlock, 1985). The disorderly, untidy physical appearances of the town that arises only once the hairdressers become occupied suggest that the unkempt public image of all individual citizens (other than Dave) is solely derived from external, situational factors that are beyond their control. Dave's disorderly public image, however, is regarded as internal, derived intrinsically from dispositions such as personality, abilities and motives.

It becomes relatively difficult for observers to employ similar sense-making processes of others as they do of themselves, particularly in instances where control is compromised (Tetlock, 1985; Cohen, 2011). The inhabitants of Here represent a collective group of perfectionists who demand certainty in an uncertain world obsessed with the concept of 'tidiness' and avoiding all of which is uncertain or ambiguous. Those with 'losing-control anxiety' attempt to control the outcome of situations, even if that means eliminating obstacles that threaten certitude (Cohen, 2011). Subjected to the innate psychological processes outlined in attribution theory, the people of Here contribute to the stigmatisation and elimination of Dave on the basis of his age and mental condition by demanding his removal from society. Rather than considering Dave's depression to be a result of an external factor such as spousal death, his mental illness is inappropriately attributed to his age.

\section{Conclusion}

Through a narrative that is built upon the flaws of society both at the social and systemic levels, Collins remarks on several dominant cultural discourses centred on mental illness as an insignificant issue, ageing as an intrinsic contribution to depression and the justification of fears about uncertainty. Deeply skilled in the art of sketching, Stephen Collins utilises his artistic ability to present an ambiguous, philosophical narrative rife with symbolism and negative space. An analysis of the 
rhetorical strategies reveals the graphic novel to be a depiction of care-giver bereavement - illustrating the depression, death anxiety and discrimination of older adults battling spousal death. Touching on psychological concepts and uniquely human tendencies, Collins demonstrates the problematic dominant discourses centred on ageism. Where the novel is entertaining and visually appealing, this particular text occupies a unique space in the media realm - one that is filled with influential content purposefully open to multiple interpretations in order to uncover the sense and meaning-making practices of not just a specific culture, but each individual reader.

\section{Note}

1 C. Bell, 'Lecture on critical race theory', 2018, personal collection of C. Bell, University of Colorado at Colorado Springs, CO.

\section{References}

American Psychiatric Association (2013) Diagnostic and Statistical Manual of Mental Disorders, 5th Edn. Washington, DC: American Psychiatric Association.

Bachner Y, O'Rourke N and Carmel S (2011) Fear of death, mortality communication, and psychological distress among secular religiously observant family caregivers of terminal cancer patients. Death Studies 35, $163-187$.

Briggs R, Tobin K, Kenny R and Kennelly S (2018) What is the prevalence of untreated depression and death ideation in older people? Data from the Irish Longitudinal Study on Aging. International Psychogeriatrics 30, 1393-1401.

Bruce M, McAvay G, Raue P, Brown E, Meyers B, Keohane D, Jagoda D and Weber C (2002) Major depression in elderly home health care patients. American Journal of Psychiatry 159, 1367-1374.

Cohen E (2011) The Fear of Losing Control: What's Behind This Fear and How You Can Overcome It. Available at https:/www.psychologytoday.com/blog/what-would-aristotle-do/201105/the-fear-losingcontrol.

Collins S (2014) The Gigantic Beard That Was Evil. New York, NY: Picador.

Edwards H and Foster E (1999) Avoidance of issues in family caregiving. Contemporary Nursing 8, 5-13.

Fleming K (2021) Persistent Complex Bereavement Disorder DSM-5. Available at https://www.theravive. com/therapedia/persistent-complex-bereavement-disorder-dsm-5.

Hoffs S and Steinberg W (1989) Eternal Flame (Song recorded by The Bangles from the album Everything) (MP3 file). Sony/ATV Music Publishing.

Kane R and Kane R (2005) Ageism in healthcare and long-term care. Generations 3, 49-54.

Kauffman J (1995) Awareness of Mortality: Death, Value, and Meaning. Amityville, NY: Baywood.

Levine H (2016) What Actually Happens to Your Hair as You Get Older. Available at https://www.prevention.com/beauty/aging-hair-myths.

McCurry J (2013) Let elderly people 'hurry up and die', says Japanese minister. The Guardian, January 22. Available at https://www.theguardian.com/world/2013/jan/22/elderly-hurry-up-die-japanese.

McKee A (2003) Textual Analysis: A Beginner's Guide. Thousand Oaks, CA: Sage.

McKee A, Collins C and Hamley B (2012) Entertainment Industries: Entertainment as a Cultural System. New York, NY: Routledge.

Miller C (2017) Hair Growth During Puberty. Available at https://www.livestrong.com/article/82865-hairgrowth-during-puberty/.

Newman K (2017) A look into older adults' state of mind: the oldest age group is growing but its supply of psychological support is dwindling. US News, October 11. Available at https://www.usnews.com/news/ best-states/articles/2017-10-11/older-adults-struggle-to-get-adequate-mental-health-care.

Nielson M, Neergaard M, Jensen A, Vedsted P, Bro F and Guldin M (2017) Predictors of complicated grief and depression in bereaved caregivers: a nationwide prospective cohort study. Journal of Pain and Symptom Management 53, 540-550. 
Rapp S, Parisi S, Walsh D and Wallace C (1988) Detecting depression in elderly medical inpatients. Journal of Consulting and Clinical Psychology 56, 509-513.

Rees WD and Lutkins SG (1967) Mortality of bereavement. British Medical Journal 4, 13-16.

Rose G (2016) Visual Methodologies: An Introduction to Researching with Visual Materials. Thousand Oaks, CA: Sage Publications.

Sherman D, Norman R and McSherry C (2010) A comparison of death anxiety and quality of life of patients with advanced cancer or AIDS and their family caregivers. Journal of the Association of Nurses in AIDS Care 21, 99-112.

Tang T, Chang W, Chen J, Wang H, Chi W, Li C and Liao Y (2013) Course and predictors of depressive symptoms among family caregivers of terminally ill cancer patients until their death. Psycho-Oncology 22, 1312-1318.

Tetlock P (1985) Accountability: a social check on the fundamental attribution error. Social Psychology Quarterly 48, 227-236.

Turner E (2014) Stephen Collins's Allegorical Fable The Gigantic Beard That Was Evil Reviewed. Available at https://biblioklept.org/2014/11/02/stephen-collinss-allegorical-fable-the-gigantic-beard-that-was-evilreviewed/.

Vess JD, Moreland JR, Schwebel AL and Knaut E (1988) Psychosocial needs of cancer patients: learning from patients and their spouses. Journal of Psychosocial Oncology 6, 31-51.

Ward J and Winstanley D (2003) The absent presence: negative space within discourse and the construction of minority sexual identity in the workplace. Human Relations 56, 1255-1280.

Wong B (2011). Negative space. Nature Methods 8, 1-1.

Cite this article: Lammon M (2021). Something old, something blue: bereavement and institutional ageism in The Gigantic Beard That Was Evil. Ageing \& Society 1-11. https://doi.org/10.1017/S0144686X21001331 